\title{
PERCUTANEOUS RADIOFREQUENCY RHIZOTOMY AND NEUROVASCULAR DECOMPRESSION OF THE TRIGEMINAL NERVE FOR THE TREATMENT OF FACIAL PAIN
}

\author{
Manoel J. Teixeira', Silvia R.D.T. Siqueira², Gilberto M. Almeida ${ }^{3}$
}

\begin{abstract}
Objective: To determine the outcomes of 354 radiofrequency rhizotomies and 21 neurovascular decompressions perf o rmed as treatment for 367 facial pain patients (290 idiopathic trigeminal neuralgia, 52 symptomatic trigeminal neuralgia, 16 atypical facial pain, 9 post-herpetic neuralgia). Method: Clinical findings and surg e rysuccess rate were considered for evaluation. A scale of success rate was determined to classify patients, which considered pain relief and functional/sensorial deficits. Results: Radiofrequency rhizotomy was performed in 273 patients with idiopathic trigeminal neuralgia and in all other patients, except for trigeminal neuropathy; neurovascular decompression was performed in 18 idiopathic trigeminal neuralgia patients; $100 \%$ idiopathic trigeminal neuralgia, $96.2 \%$ symptomatic trigeminal neuralgia, $37.5 \%$ atypical facial pain and $88.9 \%$ post-herpetic neuralgia had pain relief. Conclusion: Both techniques for idiopathic trigeminal neuralgia are usefull. Radiofrequency rhizotomy was also efficient to treat symptomatic facial pain, and post-herpetic facial pain, but is not a good technique for atypical facial pain.
\end{abstract}

KEY WORDS: facial pain, neurosurgery, trigeminal neuralgia, radiofrequency rhizotomy, vascular decompression.

\begin{abstract}
Rizotomia percutânea por radiofreqüência e a descompressão neurovascular do nervo trigêmeo no tratamento das algias faciais

RESUMO - Objetivo: Determinar eficácia e achados pós-operatórios após 354 rizotomias por radiofreqüência e 21 descompressões neurovasculares como tratamento de 367 pacientes com dor facial ( 290 neuralgia idiopática do trigêmeo, 52 neuralgia sintomática do trigêmeo, 16 dor facial atípica, 9 neuralgia pós-herpética). Método: Achados clínicos e taxa de sucesso das ciru rgias foram considerados para a avaliação. Uma escala avaliando alívio da dor e complicações sensoriais e funcionais foi utilizada para classificar os pacientes. Resultados: A rizotomia por radiofreqüência foi realizada em 273 pacientes com neuralgia idiopática do trigêmeo e em todos os outros pacientes, exceto neuropatia trigeminal; descompressão neurovascular foi realizada em 18 pacientes com neuralgia idiopática do trigêmeo; $100 \%$ dos pacientes com neuralgia idiopática do trigêmeo, $96.2 \%$ dos pacientes com neuralgia sintomática, $37.5 \%$ dos pacientes com dor facial atípica e $88.9 \%$ dos doentes com neuralgia pós-herpética tiveram alívio da dor. Conclusão: Ambas as técnicas são úteis para a neuralgia idiopática do trigêmeo. A rizotomia por radiofreqüência foi também eficiente para tratar neuralgia sintomática do trigêmeo e pós-herpética, mas não foi uma boa técnica como tratamento da dor facial atípica.
\end{abstract}

PALAVRAS-CHAVE: dor facial, neurocirurgia funcional, neuralgia trigeminal, rizotomia por radiofreqüência, descompressão neurovascular.

Idiopathic trigeminal neuralgia (ITN) is a paroxysmal shock-like pain restricted to the innervation a rea of one or more trigeminal branches, often set off by light stimuli in a trigger zone $e^{1,2}$. Its clinical treatment includes anticonvulsants, and carbamazepine is the drug of choice ${ }^{3}$, whereas surgical treatment is indicated in about $75 \%$ of the patients at any moment after diagnosis ${ }^{4}$. Around $5 \%$ of patients pres- ent an intracranial expansive lesion, which make imaging exams (computed tomography and/or magnetic resonance) necessary ${ }^{5}$. These patients characterize symptomatic trigeminal neuralgia (STN), and ne u ro su rgical treatment as the first choice. Atypical facial pain (AFP) constitutes a diverse group of patients with complex diagnosis, presenting deep and localized facial pain, often described as burning, with-

\footnotetext{
${ }^{1}$ Head of the Pain Center of Hospital das Clinicas, Functional Neurosurgery Division, Neurology Department, Medical School, University of São Paulo SP, Brazil; ${ }^{2}$ PhD Student, Member of the Orofacial Pain Team, Dentistry Division, Hospital das Clinicas, Medical School, University of São Paulo SP, Brazil; ${ }^{3}$ Neurology Department, Medical School, University of São Paulo SP, Brazil.
}

Received 10 April 2006, received in final form 28 June 2006. Accepted 12 August 2006.

Dr. Silvia R.D.T. de Siqueira - Rua Maria Candida 135 - 02071-010 São Paulo SP - Brasil. E-mail: silviadowgan@hotmail.com 
out any imaging or laboratorial abnomalities ${ }^{6}$. Postherpetic neuralgia (PHN) is a complication of Herpes zoster infection in around $4 \%$ of patients, characterized by burning pain at the trigeminal branch involv$\mathrm{ed}^{7,8}$. For both AFP and PHN, treatment with drugs (eg. antidepressants) is the first choice, but percutaneous neurosurgery may be a treatment option'. Radiofrequency percutaneous rhizotomy (RPR) is widely used to treat ITN ${ }^{10}$, and may be a choice for other recurrent facial pain ${ }^{11}$. Operated ITN may recur in $18 \%$ $20 \%$ of the cases in 10 years $^{12}$. It is probable that higher sensory deficit is an indication of higher success rate $^{13}$. Some complications are: corneal hypoesthesia (16-23\%), corneal anesthesia (2-6\%), comeal-palpe bral reflex deficit $(19,7 \%)$, keratitis (1.4-4\%), comeal ulcer (1-2\%), paresthesia (8-10.9\%), anesthesia dolorosa (0-5\%), anesthesia of trigeminal branches (17\%), Herpes simplex infection (40\%), numbness sensation (58-79\%), dysesthesia (0.5-18\% - 5\% need medication), motor masseteric deficit (4-53\%), paraliysis of ocular nerves ${ }^{14}$. Dysesthesias are usually associated to $\mathrm{m}$ o re intense sensory deficit ${ }^{15}$. Severe complications a re rare (intracranial haemorhage, meningitis) ${ }^{16}$.

Neurovascular decompression (ND) is an open surgery with the aim of eliminating the nerve compression at the entry zone by a vessel ${ }^{17}$. Most cases present immediate relief, with less than $36 \%$ of recurrence after 5 years ${ }^{18}$. Up to $26 \%$ of patients do not present the compression and need section of the trigeminal sensitive root. Complications are: facial hypoesthesia or hypoalgesia, anaesthesia dolorosa, master muscle weakness, paresis of the IV cranial nerve $(4.3 \%)$, auditive deficit ${ }^{18}$. Mortality rate is $1-$ $4.3 \%{ }^{14}$. It is indicated for young patients intending to pre se rve superficial sensitivity, suspicion of an expansive intracranial lesion, association among facial neuralgias, bilateral ITN, ITN association to hemifacial spasm; its contra-indication is multiple sclerosis ${ }^{18}$.

The objective of this study was to evaluate the outcomes of a Brazilian population of patients with ITN and other facial pains after neurosurgical treatment with RPR and/or ND.

\section{METHOD}

This study is based on the re $t$ rospective evaluation of 367 patients with facial pain treated at the Neurology Clinic of the Hospital das Clínicas, Medical School, University of São Paulo, and at the Neurosurgery Department of the Hospital Nove de Julho, São Paulo SP, between April, 1979 and June, 1984. Surgical treatment was indicated because of inefficacy and/or side effects of the clinical tre a t m e $n t$. Patiens were diagnosed according to the IASP criteria $^{19}$, and treated as followed:
G roup I: Idiopathic trigeminal neuralgia - 290 patients: 272 were treated with RPR, 17 with ND and 1 by both procedures; 1 had had RPR for PHN before, and developed ITN in other trigeminal branch.

G roup II: Symptomatic facial pain (SFP) - 52 patients: 39 with malign tumors, 7 with benign tumors, 3 with multiple sclerosis, 2 maxillary sinusopathy, 1 trigeminal neuropathy. All patients were treated with RPR, except for the last patient, which was treated with ND.

Group III: Atypical facial pain - 16 patients were treated with RPR; 2 had also ND due to pain recurrence.

G roup IV: Post-herpetic neuralgia - 9 patients, all treated with RPR.

Complementary investigation consisted in skull radiography in all patients. Computed tomography (CT) was indicated for patients younger than 40 yo, AFP, SFP, and patients with abnormal neurological exam. After 1982, all patients started to be scanned by CT. Cerebrospinal fluid (CSF) exam was performed in all patients with bilateral ITN, and in association to CT for the diagnosis of multiple sclerosis. CT of vertebral-basilar complex was performed when vascular lesions were suspected, or as a routine investigation for patients with indication of ND. Patients with other associated lesions had complementary exams, e.g. otorhinolaringologist or ophthalmologic evaluation.

\section{Surgeries}

Radiofrequency percutaneous rhizotomy - Patients undement RPR with general anesthesia or sedation, and all had previously explanation about the surgical procedure. The technique used was the one described by White and Sweet $^{20}$ and Siefgried ${ }^{9}$. After the electrode introduction, patients were awakened to inform location of the stimulated area. Stimuli generator of radiofrequency used we re the model RFG-3A (Radionics, Inc. Burlington, Massachusetts, USA) and Fundatec (Porto Alegre - Brasil). The electrode used was TIC-TM trigeminal rhizotomy electrode (Radionics, inc., Burlington, Massachusetts, USA). The final lesion was performed with general anaesthesia. Methilcelulosis eyewash was prescribed for patients with hypoesthesia of the ophthalmic trigeminal branch, for a period of 4 weeks of application. Electrophysiological data, lesion parameters, cerebrospinal fluid or blood leak through the electrode, facial hyperemia or neurological post-operative disturbances were considered during the analysis.

Neurovascular decompression - All patients were operated under inhalatory general anesthesia, and all of them we re monitorized. Surg e ry was perf o rmed with patients positioned in lateral decubit with the head inclined anterior-laterally. The trigeminal nerve root was assessed by re tromasthoida suboccipital craniotomy, and its dissection was performed using a surgical microscope. The petrous vein was electrocoagulated and sectioned in all cases, in order to facilitate the trigeminal root exposition. Veins compressing the trigeminal root were coagulated, while a rteries were dissected and separated from the root by the interposition of Teflon, Dacron or Nylon fragments ${ }^{21}$. 
Table 1. Scale for the results of RPR and ND (N=367).

\begin{tabular}{|c|c|c|c|c|c|c|c|c|c|c|c|}
\hline \multirow[t]{3}{*}{ Results } & \multicolumn{7}{|c|}{ Radiofrequency percutaneous rhizotomy } & \multicolumn{4}{|c|}{ Neurovascular decompression } \\
\hline & Degree & Degree & Degree & Degree & Degree & Degree & Degree & Degree & Degree & Degree & Degree \\
\hline & 1 & 2 & 3 & 4 & 5 & 0 & M & 1 & 2 & 3 & M \\
\hline ITN & 172 & 69 & 1 & - & 3 & - & - & 10 & 4 & 4 & - \\
\hline Unilateral & 165 & 67 & - & - & 3 & - & - & 10 & 4 & 4 & - \\
\hline Bilateral & 7 & 2 & 1 & - & - & - & - & - & - & - & - \\
\hline SFP & 16 & 9 & 6 & - & 18 & 2 & - & - & - & - & 1 \\
\hline Maligne tumours & 9 & 6 & 6 & - & 18 & - & - & - & - & - & - \\
\hline Benigne tumours & 5 & 2 & - & - & - & - & - & - & - & - & - \\
\hline Multiple sclerosis & 2 & 1 & - & - & - & - & - & - & - & - & - \\
\hline Sinusitis & - & - & - & - & - & 2 & - & - & - & - & - \\
\hline Trigeminal neuropathy & - & - & - & - & - & - & - & - & - & - & 1 \\
\hline AFP & 5 & - & 1 & - & - & 4 & 6 & - & - & 2 & - \\
\hline PHN & - & - & 8 & - & - & 1 & - & - & - & - & - \\
\hline
\end{tabular}

De gree 1: pain relief, hypalgesia or analgesia, tactile sensitivity deficit at the trigeminal branch affected, no neurological complications; Degree 2: pain relief, hypalgesia or analgesia, tactile sensitivity deficit at the branch affected and adjacent areas, minimum transient neurological complications with no functional compromise (e.g. dysesthesia, masticatory muscles paresis); Degree 3: pain relief, anaesthesia at any facial area or comeal, transient functional deficit of ocular motor nerves or other nerves, paresthesia with need of medication, lesion of encephalic structures; Degree 4: pain relief, keratitis, paresthesia with need of medication; Degree 5: pain relief, severe complications like corneal ulcers, unpleasant dysesthesia even with the use of medication, encephalic lesions;Degree 0: failure of treatment (no pain alleviation); Degree M: Partial improvement of pain or residual pain treated with medication.

Analysis - Pain relief, facial sensitivity deficit, neurological dysfunction, hypoesthesia, facial late deafferentation, clinical complications, and pain recurrence were considered for the analysis. Patients were classified in 7 degrees (Table 1). Patients were re-evaluated after 1 month, 4 months, and thereafter each 6 months. The evaluation was subjective and based on patients and relatives' information.

\section{RESULTS}

Idiopathic trigeminal neuralgia - General characteristics corresponded to literature findings ${ }^{1,2}: 166$ $(57.3 \%)$ female; $277(95.5 \%)$ white, 7 (2.4\%) yellow, $4(1.4 \%)$ black and $2(0.7 \%)$ other. Pain predominated in the right side $(57.6 \%)(p<0.05)$, and was bilateral in $17(5.9 \%)$. Ages ranged from 17-88 years old (mean 62.5 yo). Patients treated with RPR (mean age of 63.8 yo) were statistically older than patients that underwent ND (mean age of 44.8 yo) $(p<0.05)$. Mean pain duration was 91 months for ND and 99 months for RPR. Unilateral ITN distribution was: ophthalmic branch (V1) in 2.2\%, maxillary branch (V2) in 17.6\%, mandibular branch (V3) in 19.4\%, V1-2 in 19.0\%, V23 in $30.0 \%$, and $V 1-2-3$ in $11.7 \%$; 3 patients had familiar history of ITN (1.03\%). Concomitant neurological diseases were: Parkinson disease (3), essential tremor (3), cere b rovascular disorder (stroke) (2), glossopharyngeal neuralgia (2), vert e b ro-basilar invagination (1) and previous parietal meningioma (1); 8 (2.8\%) had hemifacial spasm. CT (53.4\% for RPR and $94.4 \%$ ND) findings were in general compatible to aging.
CSF exam, performed in 51 (17.6\%) patients, revealed total proteins increase in 1 patient with convulsive dis o rder (seizures). Angiography of vertebro-basilar complex was performed in 14 (4.8\%) patients and angiography of internal carotid artery in $3(1.0 \%)$ : atherosclerosis was present in 1 that had ND and 7 that had RPR.

All patients had been treated with anticonvulsants, and all had taken carbamazepine in any moment; $6.2 \%$ had never had complete pain relief with drugs, the others were indicated to surge ry due to excessive side effects or failure of drugs' efficacy; 120 $(41.4 \%)$ had previous surgical procedures: $24.8 \%$ peripheral neurotomy, $11.0 \%$ subtemporal retrogasserian mizotomy, $16.2 \%$ trigeminal peripheral alcoholization, $0.7 \%$ ND, $0.3 \%$ trigeminal ganglion alcoholization, and $0.3 \%$ ganglion electrocoagulation. Procedures were multiple in $8.2 \%$ of patients. Cardiocirculatory, respiratory, hepatic, renal or metabolic disturbances are outlined in Table 2; 19 (6.6\%) patients treated with RPR had absolute contra-indication for ND.

All patients treated with RPR had complete pain relief, although 8 had 2 RPR and 1 had 3 RPR for complete pain alleviation, immediately after the first RPR, resulting in a total of 283 procedures. Results are outlined in Table 1. Along the follow-up, pain recurrence occurred mostly in the first year (44.0\%), and was more often in patients with bilateral RPR or ITN in 
Table 2. Relevant clinical findings of patients ( $N=367)$.

\begin{tabular}{|c|c|c|c|c|c|c|c|c|c|c|}
\hline \multirow[t]{2}{*}{ Surgical risks } & \multicolumn{4}{|c|}{ Cardiac disease } & \multicolumn{2}{|c|}{ Arterial hypertension } & \multirow[b]{2}{*}{$\mathrm{D}$} & \multirow[b]{2}{*}{ DU } & \multirow[b]{2}{*}{ DB } & \multirow[b]{2}{*}{ RI } \\
\hline & $\mid \mathrm{BI}$ & ACA & IMI & $\mathrm{ICl}$ & Moderate & Severe & & & & \\
\hline \multicolumn{11}{|l|}{ ITN } \\
\hline & 14 & 11 & 17 & 25 & 107 & 40 & - & 5 & 14 & 2 \\
\hline Radiofrequency rhizotomy & 14 & 11 & 17 & 25 & 104 & 40 & - & 4 & - & 2 \\
\hline Neurovascular decompression & - & - & - & - & 3 & - & - & 1 & - & - \\
\hline SFP & 7 & - & - & - & 2 & 3 & 18 & - & - & - \\
\hline Maligne tumours & 6 & - & - & - & - & 3 & 18 & - & - & - \\
\hline Benigne tumours & - & - & - & - & 2 & - & - & - & - & - \\
\hline Multiple sclerosis & 1 & - & - & - & - & - & - & - & 1 & - \\
\hline Sinusitis & - & - & - & - & - & - & - & - & - & - \\
\hline Trigeminal neuropathy & - & - & - & - & - & - & - & - & - & - \\
\hline \multicolumn{11}{|l|}{ AFP } \\
\hline & 2 & - & - & - & 3 & - & - & - & 1 & - \\
\hline Radiofrequency rhizotomy & 3 & - & - & - & 3 & - & - & - & 1 & - \\
\hline Neurovascular decompression & - & - & - & - & - & - & - & - & - & - \\
\hline PHN & 3 & - & - & - & 2 & 2 & - & 1 & - & 1 \\
\hline
\end{tabular}

ITN, idiopathic trigeminal neuralgia; SFP, symptomatic facial pain; AFP, atypical facial pain; PHN, post-herpetic neuralgia; IBI, breathing chro nic insufficiency; CA, cardiac arrhythmia; MI, myocardial isquemia; Cl, cardiac insufficiency; D, de-nutrition; DU, duodenal ulcer; DB, diabetes; RI, renal insufficiency.

more than 1 branch $(p<0.05)$, but not associated to the degree of post-operative sensorial deficit: $13.5 \%$ of patients with post-operative hypoalgesia, $18.9 \%$ with partial analgesia, and $44.5 \%$ with complete analgesia had recurrence. Recurrence and complications a re outlined in Table 3. Transient trigeminal paresis occurred in 13 (4.8\% - but only 1 discomfortable), and facial paresthesia occurred in 36 (13.2\%); $2.8 \%$ had anaesthesia dolorosa. Numbness sensation was unpleasant in $8(2.9 \%)$ patients; $4(1.5 \%)$ had diff $\mathrm{i}-$ culties to adapt their dental prosthesis due to facial hypoesthesia; $10(3.7 \%)$ had ulcerate lesions in the oral mucosa clinically treated. Transient functional deficit of the VI cranial nerve occurred in $3(1.1 \%)$ patients and of the IV nerve in $1(0.4 \%) ; 4(1.5 \%)$ had transient gustatory deficit and $18(6.6 \%)$, transient auditive disturbances; $1(0.4 \%)$ had haematoma of the right temporal lobe due to accidental cerebral cortex injury. Fortunately, he got completely well after surgical treatment. Sensitive deficits are outlined in Table 4. Hypalgesia/analgesia were transient in $30.4 \%$ fo patients (Table 5). Follow-up of patients was up to 65 months (mean 22.6 months).

All patients treated with ND got complete pain relief (Table 1): 1 had still 2 days of paroxysms. Neurovascular conflict was present in all of them: $17(94.4 \%)$ with the superior cerebellar artery, $3(16.7 \%)$ with anterior-inferior cerebellar art e ry, $1(5.6 \%)$ vertebral artery, $1(5.6 \%)$ undetermined vein, and $2(11.1 \%)$ arachnoiditis. Only 3 (16.7\%) had depression of neural surface at the compression area, and compression was located in all at the initial $5 \mathrm{~mm}$ of the trigeminal root. Only 1 (5.6\%) had recurrence, after 30 months (Table 3). Follow-up was up to 39 months (mean of 25.5 months).

Symptomatic facial pain - The most prevalent gender was male (30 patients - $75.8 \%$ ); all patients were white; ages ranged from 22-77 yo (mean 56.5 yo). Breathing insufficiency, hypertension and/or de-nutrition were present in 30 cases (Table 2). Recurrence rates $(9.6 \%)$ and complications may be observed on Table 3.

a) Malign tumors $(\mathrm{N}=39)$ : Tumor location was: cranial base, oral cavity, face, oropharynx and larynx. All patients had RPR as treatment, and all had pain relief (Table 1). Pain distribution was: V3 in 17 (43.6\%), V2-3 in $10(25.6 \%), V 1-2-3$ in $6(15.4 \%), V 1-2$ in 3 $(7.7 \%)$, V2 in $2(5.1 \%)$, V1 in $1(2.6 \%)$. RPR was bilateral in $3(7.7 \%)$ patients. Three patients had lesion of adjacent branches during the procedure. Followup was up to 23 months (mean 5.2 months).

b) Benign tumors ( $\mathrm{N}=7$ ): One patient had meningioma of Meckel cave, 2 meningioma of the medium and posterior fossa, 1 clivus meningioma, 1 dermoid cyst of Meckel cave (with previous surgery without alleviation), and 1 acoustic neurinoma. All were treated with RPR, and all had pain relief (Table 1). 
Table 3. Pain recurrence and complications $(N=367)$.

\begin{tabular}{|c|c|c|c|c|c|c|c|c|c|c|c|c|}
\hline Results & $\mathrm{N}$ & $\mathrm{N}^{\circ}$ & $\%$ & MT & $\mathrm{CH}$ & $A C$ & MC & $\mathrm{K}$ & U & $\mathrm{CP}$ & CE & OT \\
\hline ITN & 290 & 29 & 9.6 & 14 & 39 & 6 & 13 & 2 & 1 & 36 & 5 & 56 \\
\hline Radiofrequency rhizotomy & 273 & 28 & 10.2 & 13 & 39 & 6 & 13 & 2 & 1 & 36 & 4 & 49 \\
\hline Neurovascular decompression & 18 & 1 & 5.6 & 30 & - & - & - & - & - & - & 1 & 7 \\
\hline SFP & 52 & 6 & 9.6 & 9.5 & 2 & - & 1 & 1 & 2 & 2 & 1 & - \\
\hline Maligne tumours & 39 & 3 & 5.1 & 3 & - & - & 1 & 1 & 1 & 2 & 1 & - \\
\hline Benigne tumours & 7 & 2 & 28.5 & 15 & - & - & - & - & - & - & - & - \\
\hline Multiple sclerosis & 3 & 1 & 33.0 & 12 & 1 & - & - & - & - & - & - & - \\
\hline Sinusitis & 2 & - & - & - & 1 & - & - & - & 1 & - & - & - \\
\hline Trigeminal neuropathy & 1 & - & - & - & - & - & - & - & - & - & - & - \\
\hline AFP & 16 & $4^{*}$ & 23.5 & 12 & 1 & - & - & 1 & - & 2 & 1 & 1 \\
\hline Radiofrequency rhizotomy & 16 & 3 & 23.5 & 12 & 1 & - & - & 1 & - & 2 & - & 1 \\
\hline Neurovascular decompression & 2 & 1 & 50.0 & 6 & - & - & - & - & - & - & 1 & - \\
\hline PHN & 9 & - & - & - & - & - & - & 1 & 2 & - & - & 1 \\
\hline
\end{tabular}

ITN, idiopathic trigeminal neuralgia; SFP, symptomatic facial pain; AFP, atypical facial pain; PHN, post-herpetic neuralgia; N, number of patients; No, number of recurrences; \%, percentage of recurrences; MT, mean duration of recurrence (months); $\mathrm{CH}$, corneal hyporeflex; $\mathrm{AC}$, abolition of comeal reflex; $\mathrm{MC}$, compromise of motor root; $\mathrm{K}$, keratitis; $\mathrm{U}$, corneal ulcer; $\mathrm{CP}$, central pain; $\mathrm{CE}$, compromise of extrinsic motility of the eye; $\mathrm{OT}$, other; * patient that underwent both surgeries.

Table 4. Sensitive post-operative deficits after RPR X trigeminal branch affected ( $N=290)$ : sensitive deficits occurred in a different trigeminal branch than the pain location in 40 (14.7\%).

\begin{tabular}{lcccccccc}
\hline \multicolumn{7}{c}{ Area of sensitive deficit } \\
\hline Trigeminal & & V1 & V2 & V3 & V1-2 & V2-3 & V1-2-3 & Sub-total \\
branch & V1 & 5 & - & - & - & - & 1 & 6 \\
affected & V2 & - & 31 & - & 3 & 12 & 3 & 49 \\
by pain & V3 & - & - & 44 & - & 7 & 1 & 52 \\
& V1-2 & - & 2 & - & 43 & - & 9 & 54 \\
& V2-3 & - & 1 & 2 & 2 & 72 & 4 & 81 \\
& V1-2-3 & - & - & 1 & 1 & 4 & 25 & 31 \\
\hline
\end{tabular}

c) Multiple sclerosis $(\mathrm{N}=3)$ : Facial pain began after 2-20 years from the initial symptoms of the disease, and pain duration ranged from 12 to 39 months (mean 29m); 2 patients had bilateral ITN and 1 unilateral AFP; 2 had pain at V3 and 1, V1-2. Neurological abnormalities including facial hypoesthesia were $p$ resent in all of them. All underwent RPR, with initial pain relief (Table 1). Maximum follow-up was 56 months (mean $30.7 \mathrm{~m}$ ).

d) Sinusitis ( $\mathrm{N}=2$ ): Pain was at V1-2 in 1 and at V2 in the other. Both had multiple unsuccessful previous treatments. No one had pain alleviation after RPR (Table 1).

e) Trigeminal neuropathy ( $\mathrm{N}=1$ ): Pain was present on the left side, associated to moderate hypoesthesia. Previous treatments with anticonvulsants and psychotrpics were unsuccessful. Imaging exams and blood tests were normal. ND was perfo rmed because of arachnoiditis observed on imaging exams, but its coagulation did not relief pain (Table 1).
Atypical facial pain - Half patients were female (8; $50 \%)$, and all were white. Pain was on the left facial side in $8(50 \%)$ and bilateral in $1(6.3 \%)$. Ages ranged from 29 to 79 yo (mean 55.6 yo). Pain started mostly between the fifth and sixth life's decade. It was located at V1 in $2(12.5 \%)$, at V2 in $1(6.3 \%)$, at $\mathrm{V} 3$ in $3(18.8 \%)$, at $\mathrm{V} 1-2$ in $2(12.5 \%)$, at $\mathrm{V} 2-3$ in 5 $(31.3 \%)$ and at $\mathrm{V} 1-2-3$ in $3(18.8 \%)$. Findings were normal in imaging exams. Previous surgeries were: $6(37.5 \%)$ trigeminal neurecto my, $6(37.5 \%)$ subtemporal mizotomy, and $1(6.3 \%)$ peripheral trigeminal alcoholization. Associated diseases are outlined in Table 2, and post-operative complications in Table 3. All were treated with RPR, but only $37.5 \%$ had pain relief (Table 1). Six (37.6\%) had lesion of adjacent trigeminal branches during surgery. Two patients with recurrence had complete pain relief after ND. Patients with degree 0 were treated with trigeminal tractotomy and nucleotomy without improvement. Follow-up ranged from 3 to 62 months (mean $33.4 \mathrm{~m}$ ). 
Table 5. Pain location $X$ post-operative analgesia $(N=221)$ and hypoalgesia $(N=114)$, after radiofrequency percutaneous rhizotomy.

\begin{tabular}{|c|c|c|c|c|c|c|c|c|c|}
\hline \multirow{5}{*}{$\begin{array}{l}\text { Trigeminal } \\
\text { branch } \\
\text { affected } \\
\text { by pain }\end{array}$} & \multicolumn{9}{|c|}{ Location of post-operative analgesia $(\mathrm{N}=221)$} \\
\hline & & V1 & V2 & V3 & V1-2 & V2-3 & V1-2-3 & V1-3 & Sub-total \\
\hline & V1 & 1 & - & - & - & - & 1 & - & 2 \\
\hline & V2 & - & 32 & - & 2 & 6 & - & - & 40 \\
\hline & V3 & - & 1 & 32 & - & 5 & 1 & - & 43 \\
\hline & V1-2 & - & 21 & - & 15 & 1 & 4 & - & 41 \\
\hline & V2-3 & - & 6 & 13 & 1 & 47 & 4 & - & 71 \\
\hline & V1-2-3 & - & 4 & 2 & - & 10 & 7 & 1 & 24 \\
\hline & \multicolumn{9}{|c|}{ Location of post-operative hypoalgesia $(\mathrm{N}=114)$} \\
\hline Trigeminal & & V1 & $\mathrm{V} 2$ & V3 & V1-2 & V2-3 & V1-2-3 & V1-3 & Sub-Total \\
\hline branch & $\mathrm{V} 1$ & 4 & - & - & - & - & - & - & 4 \\
\hline affected & V2 & 2 & 6 & 2 & - & 3 & - & 1 & 14 \\
\hline by pain & V3 & 1 & - & 8 & - & - & - & - & 91 \\
\hline & V12 & 15 & - & 1 & 13 & - & - & 4 & 33 \\
\hline & V2-3 & 2 & 9 & 5 & 2 & 11 & 1 & 2 & 32 \\
\hline & V1-2-3 & 9 & 1 & 2 & 3 & - & 5 & 2 & 22 \\
\hline
\end{tabular}

Post-herpetic neuralgia - Most patients were male $(55.6 \%) ; 8(88.8 \%)$ were white. Ages ranged from 26 to 88 yo (mean 61.7 yo). Pain location was at V1 in 8 patients and V3 in 1. All had tactile hypoesthesia and allodynia at the affected area. Only 2 had previous surgical treatment (1 had peripheral neurectomy and the other peripheral V1 alcoholization). After RPR, $88.8 \%$ had pain relief (Table 1 ). Associated diseases a re outlined in Table 2, and post-operative complications in Table 3. During the procedure, 4 (44.4\%) patients had adjacent lesion at V2. Three needed further trigeminal tractotomy and nucleotomy after re cu rrence, but only one had pain relief. The others underwent thalamotomy with partial improvement. Follow-up ranged from 3 to 60 months (mean $25.1 \mathrm{~m}$ ).

\section{DISCUSSION}

Neurosurgical proce du res have a recognized efficacy in the treatment of facial pain, especially for ITN. The ideal surg ery should eliminate pain with low risks and post-operative complications, including few cases of recurrence. There are a lot of controversies on the indication of surgical techniques ${ }^{17,21}$ and on hypothetical etiologies and their treatment ${ }^{22}$. For ITN, the current techniques include RPR (apercutaneous procedure) ${ }^{14}$ and ND (an open surgery) ${ }^{21}$. Percutaneous techniques are very safe, and facial pain often affects elderly people with higher surgical risks.

In this sample, general characteristics of the patients, including gender, age, ethnic group, and pain characteristics (side, branch affected, pain location, duration) are similar to scientific literature ${ }^{1,2,10}$. Patients selected for ND were usually younger and did not present clinical contra-indications to an open surgery. Only 1 patient in this sample had more than 60 years old, but he had association of hemifacial spasm to ITN, which was the reason for ND' .

RPR was indicated for older ITN patients with higher clinical risks for complications, and other pain causes (SFP, AFP, PHN) ${ }^{23}$. For these cases, there is no advantage using more invasive techniques, and the chosen procedure should be as simpler and safer as possible. All patients had information about types of s u rgeries, their advantages, disadvantages and risks, and could participate during the proce du re's choice. Many patients with ND indication chose RPR because of their risks fear.

All complications that occurred in this sample we re similar to literature ${ }^{13,17,18}$. Carotid lesion occurred in $2.9 \%$ of the cases, but did not cause permanent damage. There was a variable degree of tactile hypoesthesia after RPR. Corneal sensory deficit was more frequent in patients with ITN at V1 (31.4\%). Complaints of impossibility of bilateral mastication may occur due to oral mucosa hypoesthesia, and lingual hypoesthesia may difficult dental prothesis adaptation. The low rate of motor complications after RPR may be associated to large nerve fibers presenvation. Beyond that, we did not observe any association between the degree of hypoesthesia and the recurrence rate ${ }^{24}$.

When surgery is indicated to ITN, it usually presents high rate of success ${ }^{10,15,24}$. In this study, RPR and ND relieved ITN in $100 \%$, and RPR reduced symptomatic facial pain in $94.8 \%$ immediately after the surgery. The presence of a primary case, like multiple 
sclerosis, indicates RPR rather than ND, because of the non evidence of a vascular compression as etiology $^{18}$. On the other hand, other facial pain causes without a removable cause (eg. AFP, PHN), or tumors impossible to extirpate, do not often present good results with drugs, and surg e ry may be a choice ${ }^{8}$. In this study, $81.3 \%$ AFP and $88.9 \%$ PHN patients had partial or complete pain relief, but neurosurgerywas not efficient for inflammatory disease (sinusitis) or trigeminal neuropathy.

Dysesthesias and other sensory complications of these sample were more often after RPR, corresponding to other scientific papers, but immediate complications after ND are usually more severe ${ }^{12,13,21}$. Despite that, ND may be a good choice for young patients intending to prese ne superficial facial sensitivity, which is an unpleasant complaint, and dysesthesia in these cases is uncommon. The recurrence rate of ND is also lower than RPR ${ }^{21}$.

In conclusion, both procedures were useful to treat ITN, and age, clinical conditions, and patients' opinions are the factors that should be considered during the surgical choice. RPR was also efficient to treat symptomatic facial pain and post-herpetic facial pain, but not atypical facial pain and inflammatory pain (sinusitis).

\section{REFERENCES}

1. Rothman KJ, Monson RR. Epidemiology of trigeminal neuralgia. J Chron Dis 1973;26:2-12

2. Siqueira SRDT, Nóbrega JCM, Valle LBS, Teixeira MJ, Siqueira JTT. Idiopathic trigeminal neuralgia: dinical aspects and dental procedures. Oral Surg Oral Med Oral Pathol Oral Radiol Endod 2004;98:311-315.

3. Guerrero-FiqueroAR, Escobar-Juyo A, Caballero-Garda G, BlancoCastillo IP. Gabapentin effect in orofacial allodynia: experimental correlation with trigeminal neuralgia. Rev Neurol 1999;29:1147-1153.

4. Zakrzewska JM, Patsalos PN. Long-term cohort comparing medica (oxcarbazepine) and surgical management of intractable trigeminal neuralgia. Pain 2002;95:259-266.

5. Benedittis G, Bernasconi V, Ettore G. Tumours of the fifth cranial nerve Acta Neurochir (Wien) 1977;38:37-64
6. Zakrzewska J. M. Classification issues related to neuropathic trigeminal pain. J Orofac Pain 2004;18:325-331.

7. B rown GR. Herpes zoster: correlation of age, sex, distribution, neuralgia, and associated disorder. South Med 1976;69:576-578

8. Gerson RG. The management of post-herpetic neuralgia. In Murphy JE (ed). Pharmaceutical medicine. London; 1979:177-185.

9. Siegfried J. 500 percutaneous thermocoagulation of the Gasserian ganglion for trigeminal pain. Surg Neurol 1977;8:126-131.

10. Choudhury BK, Pahari S, Acharyya A, Goswami A, Bhattacharyya MK Percutaneous retrogasserian radiofrequency thermal rhizotomy for trigeminal neuralgia. J Indian Med Assoc 1991;89:294-296.

11. Mathews ES, Scrivani SJ. Percutaneous stereotactic radiofrequency thermal rhizotomy for the treatment of trigeminal neuralgia. Mt Sinai J Med 2000;67:288-299.

12. Taha JM, Tew JM. Comparison of surgical treatments for trigeminal neuralgia: Reevaluation of radiofrequency rhizotomy. Neurosurg 1996; 38:865-871.

13. Peters G, Nurmikko TJ. Peripheral and gasserian ganglion-level precedures for the treatment of trigeminal neuralgia. Clin J Pain 2002;18: 28-34.

14. Pollock BE, Foote RL, Stafford SL, Link MJ, Gorman DA, Schomberg PJ. Results of repeated gamma knife radiosurgery for medically unresponsive trigeminal neuralgia. J Neurosurg 2000;93(Suppl 3):S162-S164.

15. Taha JM, Tew JM, Buncher R. A p rospective 15-year follow up of 154 consecutive patients with trigeminal neuralgia treated by percutaneous ste reotactic radiofrequency thermal rhizotomy. J Neurosurg 1995;83: 989-993.

16. Bilgin H, Kelebek N, Korfali G, Bekar A, Kerimogl U. A r a recomplication of trigeminal nerve stimulation during radiofrequency thermocoagulation. J Neurosurg Anesthesiol 2002;14:47-49.

17. Kanpolat $Y$, Savas A, Bekar A, Berk C. Percutaneous controlled radiofrequency trigeminal rhizotomy for the treatment of idiopathic trigeminal neuralgia; 25-years experience with 1600 patients. Neurosurgery 2001;48:524-534.

18. Pollack IF, Janetta PJ, Bissonette DJ. Bilateral trigeminal neuralgia: a 14 -years experience with microvascular decompression. J Neurosurg 1988;68:559-565.

19. Merskey H, Bogduk N. Classification of chronic pain. $2^{\mathrm{a}}$. Ed. Seattle: IASP Press, 1994

20. White JC, Sweet WH. Pain and the neurosurgeon. Illinois: Charles C Thomas Publisher, 1969.

21. Jannetta PJ. Vascular decompression in trigeminal neuralgia. In Samii M, Jannetta PJ (eds). The cranial nerves. Berlin: Spriger-Verlag, 1981:331340

22. Hitchocock H, Teixeira M, Pinto J. Percutaneous trigeminal radiofrequency rhyzotomy. J Royal Coll Surg Edinburgh 1983;28:74-79.

23. Yoon KB, Wiles JR, Miles JB, Nurmikko TJ. Long-term outcome of percutaneous thermocoagulation for trigeminal neuralgia. Anaesthesia 1999:54:798-808.

24. Salar G, Mingrino S, Iob I. Alterations of facial sensitivity induced by perataneous thermocoagulation for trigeminal neuralgia. Surg Neurol 1983;19:126-130. 